窒素ガス下の燃焼反応プロセスによる $\mathrm{TiAl}$ 基複合材料の合成

大阪府立大学 工学部

大阪府立大学 大学院 [(現) 住友金属工業(侏)]
間㴊博, 中山 豊

泰山 正則

Hiroshi Mabuchi, Masanori Yasuyama and Yutaka Nakayama : Preparation of TiAl-base Composites by the Combustion-reaction Process under a Nitrogen Gas.

The composites were prepared from elemental powders, i.e. titanium powders and aluminum powders. The powder mixtures, with a conposition $\mathrm{Ti}_{50} \mathrm{Al}_{50}$ (in atoaic $\%$ ), were cold isostatically pressed, and sintered under a nitrogen gas of $0.1 \mathrm{MPa}$ for a time of 5 min at $1273 \mathrm{~K}$. Consequently, (TiAl+Ti${ }_{3} \mathrm{Al}$ ) and $\mathrm{Ti}_{2} \mathrm{AlN}$ were produced by the combustion-reaction, and the resulting composite had about 30 vol\% $\mathrm{Ti}_{2} \mathrm{AlN}$ in the matrix $\mathrm{TiAl}$. It was found that the composites have good strength and ductility at both room and elevated tenperatures. Therefore, present investigations have considarable interest as a new conbustion-reaction process to make a composite material. (Received August 1,1990 )

I 粕 言

TiAl 金属間化合物は，軽量酎熟榑造材料として現在も つとも期待されている材料の一つであるが,これら金蚛間 化合物を実用化していくためには常温での性と高温强度 を確保することが不可久である。この制性と高沮强度を改 善するため，最近，ボライド $\left(\mathrm{TiB}_{2}\right)$ のような第 2 相を含 む被合組織材料にしてこの化合物を利用する武みがなされ ている゙。

ところで，裸合組糡材料を作毁するには，一般に襩合化 される材料，例えばセラミックスなとをを通当に配列あるい は分散させたのち，これらをマトリックスとともに固化成 形させる方法が探られる。しかし，このようにして作彆し た被合材料ではマトリックス相と䙡合化された相との間に 密着性あるいは界面反応などの問題が生じてくることが多 い。したがって、これら界面状臨を制御した製造方法の開 発が重要な研究課题の一つになっている。一方, 热的な平 猴相として存在する梖合組織を利用する場合には，然的安 定性の高い䘽合相が得られ，界面反応などの問厥も生じな い。一方向凝固被合材料などがその例であるが，この埸合 には選択される合金系が比较的限定され，その製造方法も 高度な技術を要求するものが多い。

このような中で，本研究は，マトリックスを秦䉼末の嘴 烧反応で合成できる金属間化合物 TiAl とし，きらにこの 燃㹸反応を窒素ガス下で行うことにより，同時に窒化物を 合成してin-situ で福合材料化させることを試みた。本報 では，その合成方法と得られた被合材科の組維ならびに基 磁的な特性を述べることにする。

\section{II実筷方 法}

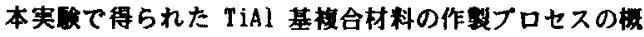
略をFig. 1 に示す。

原料粉末としては通常市肘の純度99.5 nass\%, 325 wesh

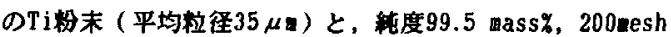

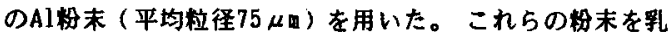
鉢中でTiAl化学量諭組成の割合で湿台し、これを約140MPa の圧力で成形して直径9ma，高さ10amの圧枌体を作製した。 この圧妢体を石英篔に捅入し，具空排気 $\left(\sim 1 \times 10^{-4} \mathrm{~Pa}\right)$ したのち，窒素ガス（純度99.999\%以上）を0.1MPa（約1気 圧）になるように充填し，1273Kの電気炉中で0.3ks保持（ 試料の昇沮速度は $30 \mathrm{~K} / \mathrm{sec})$ することにより妻粉末を燃焼

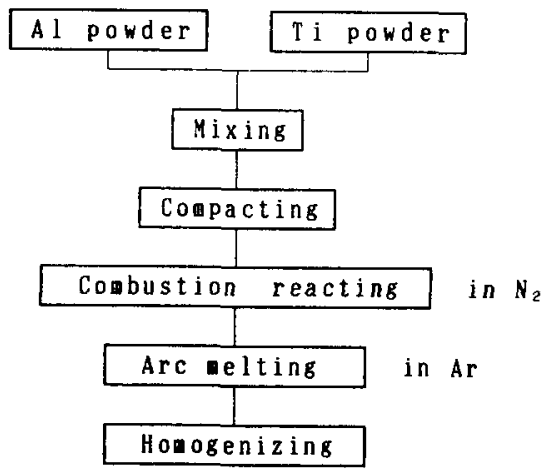

Fig. 1 Specimen preparation. 
反底させて焼結体を待た。この烧結体についてCu-K $\alpha$ 線に

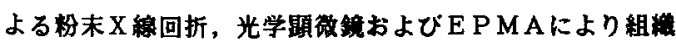
分析を行った。さらに，得られた梳結体を数個あわせてア ルコン雾囲気中でーク溶解し，約40g のボタンインゴッ トとした。これらインゴットは，ます鎛造状隗のままで光

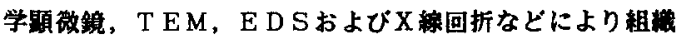
分析を行い，つついて1423K，20h因一化焼跑した武料につ

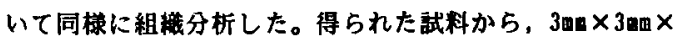
6m の角柱状武片を切り出し，インストロン型武驗機を用 いて 室温 $1473 \mathrm{~K}$ ，ひずみ速度 $5.5 \times 10^{-4} \mathrm{~s}^{-1}$ で压緗試 を行った。

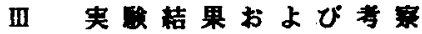

\section{IIII-1燃焼反店遇程}

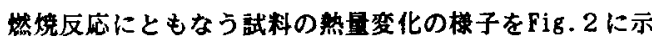
した。ここでは， $\mathrm{Ti}_{50} \mathrm{Al}_{50}$ 組成の混合粉末の一部（粷1008） を示差热分析装置に入れ，真架中および窒菜ガス中で20K/ 四们の昇温速度で加愁したときの第量変化を示している。 真空中の場合には，A1の融点直前で発鳌反応がみられ，固 相状態で焱焼反応が生じたことを示している。その発舤量 は比較的小さく，得られた焼結体は $0.5 \mathrm{~mm}$ 程度の粒からな る多孔筫体であった。一方，望絜ガス中ではA1の虽解によ る吸鶖反応を経た後，1000K 付近で大きな発鶖反応が生じ ている。この場合の反応は激しく，焾烧生成物は溶け落ち た状態であった。

つぎに，Fig. 3 は圧粉体の中央部に热電对を挿入し，窒 素ガス中，30K/sec の昇温速度で加热したときの試料温度 の変化を示す。图より，然烧反応はAlの融解が生じた後の 約993Kより急激に始まり，試料温度は鶖電対の测定範国を 越えた 2000K以上まで達している。また, 温度ピークは数

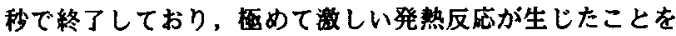
示している。

このように，窒秦ガス下では真秦が燃烧反応に関䋆して

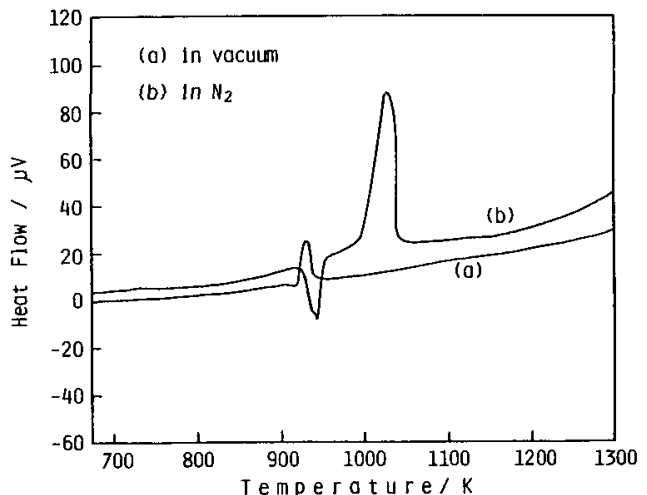

Fig. 2 DTA curves of $\mathrm{Ti}_{50} \mathrm{Al}_{50}$ compact specimen; (a) in a vacuum, (b) in a nitrogen gas.

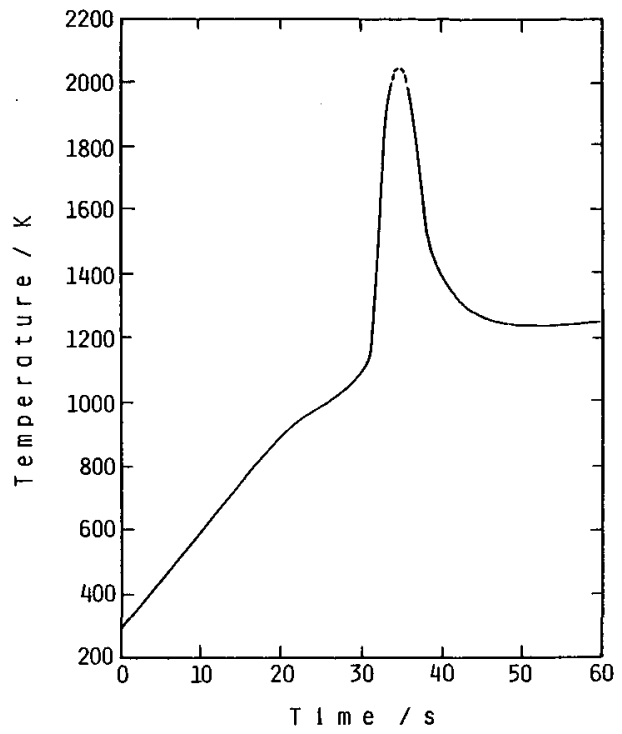

Fig. 3 Temperature changes of a $\mathrm{Ti}_{50} \mathrm{Al}_{50}$ compact specimen with exothermic reaction under a nitrogen gas.

いることは明らかであり，潡しい発熱反応は生成热の大き い窒化物が形成されたためと思われる。また，咥素がス中 の反応が真空中と比較して高温溯になる原因は，真空中で

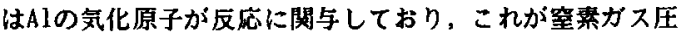
カ下で抑えられたためてはないかと考えられる。

\section{III-2 燃烧反店生成物}

Fig. 4 に $\mathrm{Ti}_{50} \mathrm{Al}_{50}$ 組成の武料について知㜔反応により得 られた生成物の粉末X線回折の結果を示す。真空中で㞺焼 反応させた場合には, TiAl $(\gamma)$ 相と少量のTi ${ }_{3} A l\left(\alpha_{2}\right)$

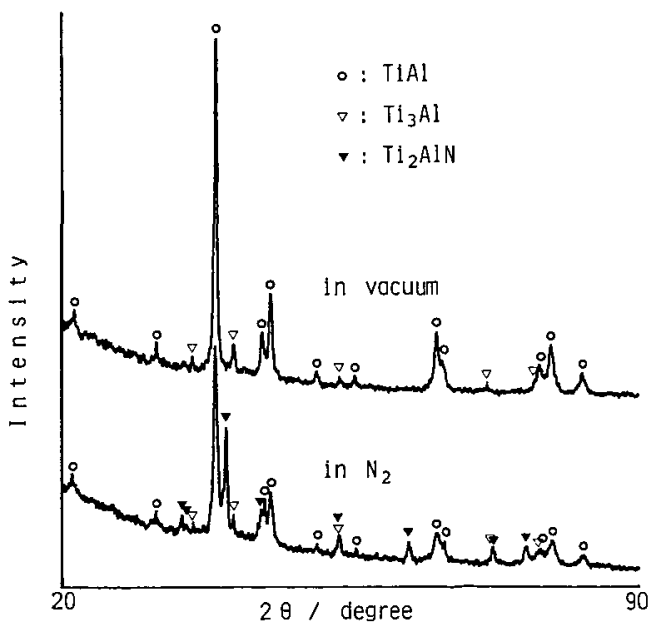

Fig. 4 X-ray diffraction patterns of the reaction products for $\mathrm{Ti} 50^{\mathrm{A}} 1_{50}$ compact specimens. 
相が生じている。一方，窒素ガス中で然烧反応させた㧹合 には, TiAl相および少量の $T i_{3} A 1$ 相の他に, 化合物 $\mathrm{Ti}_{2} \mathrm{AlN}$ の強い回折ピークが琴められる。この窒化物 $\mathrm{T}_{2}$ AlNは，そ の報告例は少ないが 2) 〜)，TiN と類似し太性㙺を有する ことが知られている゙。

本実駼では, Ti 粉末とAl 粉末の混合比を変えた試料に ついても同様の然焼反応がみられたので,これらの生成物 についてもX線回折により調查した。その結果をまとめて Table 1 に示す。いすれも, 所定の混合比 (原子比率) の 素粉末圧粉体を窒素ガス中，1273Kの炉中に描入して 5 m in 保持して得られた生成物である。このように Ti-rich側か 5 Al-rich側まで 8 種類の生成物が磼琵され，混合比に対

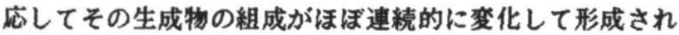
るのが特徵といえる。本実験ではTiAl $(\gamma)$ 相がマトリッ クスとなる混合比に着目し, $\mathrm{Ti}_{50} \mathrm{Al}_{50}$ 組成の試料について 検誩した。

Table 1 The reaction products under a nitrogen gas for Ti-Al compact specimens with various compositions.

\begin{tabular}{|c|c|c|c|c|c|c|c|c|}
\hline Somple & $\mathrm{T} 1$ & TiN & $\mathrm{Tl}_{3} \mathrm{Al}$ & $\mathrm{Ti}_{2} \mathrm{AlN}$ & TIAI & $\mathrm{TIAl}_{2}$ & $\mathrm{TIAl}_{3}$ & AIN \\
\hline $\mathrm{Tl}_{75} \mathrm{Al}_{25}$ & 0 & 0 & ( & ๑ & $x$ & $x$ & $x$ & $\times$ \\
\hline $\mathrm{TI}_{67} \mathrm{Al}_{33}$ & 0 & 0 & ( & 0 & $x$ & $x$ & $x$ & $\times$ \\
\hline $\mathrm{TI}_{50} \mathrm{Al}_{50}$ & $x$ & $\times$ & 0 & 0 & 0 & $x$ & $x$ & $x$ \\
\hline $\mathrm{TI}_{33} \mathrm{Al}_{67}$ & $x$ & $x$ & $x$ & 0 & 0 & (ब) & $x$ & $\times$ \\
\hline $\mathrm{Ti}_{25} \mathrm{Al}_{75}$ & $x$ & $x$ & $x$ & $x$ & $x$ & 0 & (ब) & 0 \\
\hline
\end{tabular}

\section{III-3 燃焼反応した試料の組緒}

Fig. 5 に $\mathrm{Ti}_{50} \mathrm{Al}_{50}$ 組成の混合粉末を窒絜カス中で燃烧反 応して得られた武料の光学顥微鏡組織を示す。写真にみら れるように, 幅 $1 \sim 2 \mu \mathrm{m}$, 長さ $10 \mu \mathrm{n}$ 以下の棒状の析出物が 微細かつ緻密に分散した複合組織を形成している。析出物 の体積率は約 $30 \%$ であった。この組織から E P M Aによる 組成分析による結果をTable 2 に示す。析出物はTi,Al,Nの 組成比がほぼ $2 ： 1 ： 1$ であることから,この生成物は化 学量論組成からなる窒化物 $\mathrm{Ti}_{2} \mathrm{AlN}$ 代あることが確琵できる。 マトリックスは Al-richになっているが, X線回折の結果 から大部分が $\mathrm{TiAl}$ 相であり, 一部 $\mathrm{Ti}_{3} \mathrm{Al}$ 相が存在している と考えられる。また, マトリックスにも窒妻が約 4 \% 含ま れている。窒秦は TiAl 相にはほとんど固溶しないが3),

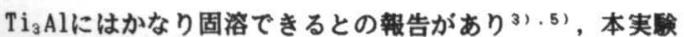
の分析で得られたマトリックス中の荎素はほとんど $\mathrm{Ti}_{3} \mathrm{Al}$ に固溶しているものと推糊される。

\section{III-4 アーク溶解した試料の組継}

以上のように, $\mathrm{Ti}_{50} \mathrm{Al}_{50}$ 組成では窒絜カス下の燎焼反応

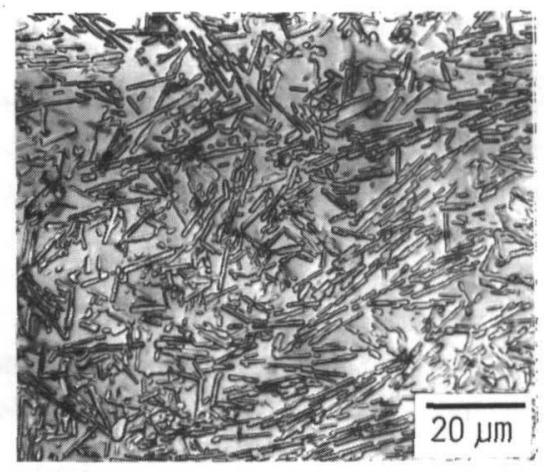

Fig. 5 Optical microstructure of the reaction products for a $\mathrm{Ti}_{50} \mathrm{Al}_{50}$ compact specimen.

Table 2 EPMA analysis results ( atomic 8 ) of the reaction products in a nitrogen gas for a $\mathrm{Ti}_{50} \mathrm{Al}_{50}$ specimen.

\begin{tabular}{cccc}
\hline \multirow{2}{*}{ Sample } & \multicolumn{3}{c}{ Compositlon, at \% } \\
\cline { 2 - 4 } & $\mathrm{T} 1$ & $\mathrm{Al}$ & $\mathrm{N}$ \\
\hline Prec1pl tate & 50.1 & 25.1 & 24.8 \\
Matrix & 46.1 & 50.2 & 3.7 \\
\hline
\end{tabular}
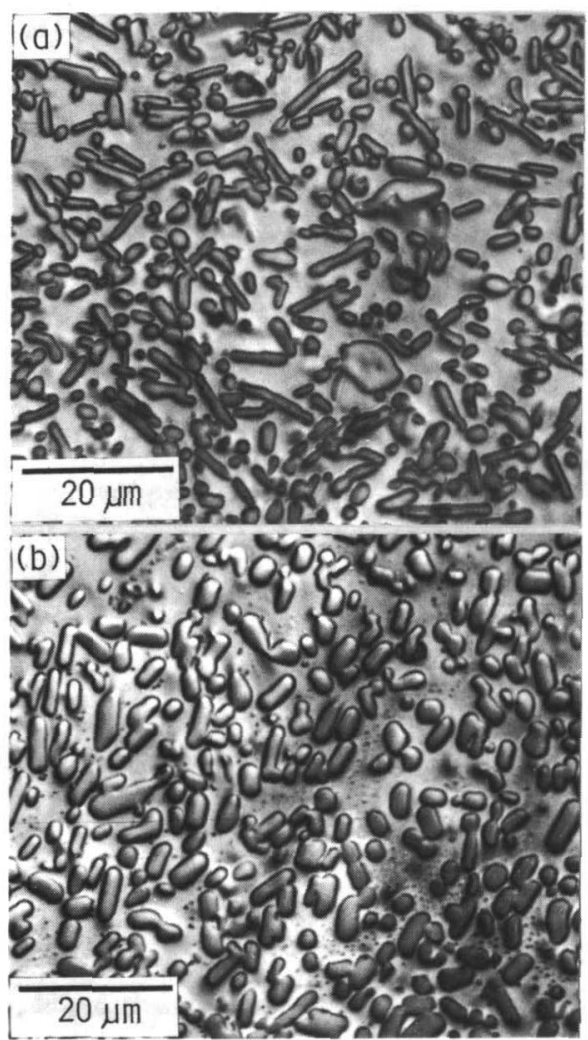

Fig. 6 Optical microstructures of a $\mathrm{Ti}_{50} \mathrm{Al}_{50}$ specimen prepared from combustion-reaction process followed by arc-melting; (a) as cast specimen, (b) annealed specimen. 
により窒化物 $\left(\mathrm{Ti}_{2} \mathrm{AlN}\right)$ がマトリックス $\left(\mathrm{TiAl}+\mathrm{Ti}_{3} \mathrm{Al}\right)$ 中 に微細分散した被合材料となることがわかった。しかし， すでに述べたように, 得られた試料は然烧反応がきわめて 激しいため試料中に多数の空洞が生じ, 徽密なインゴット 状にはならない。このため, 圧縮試験片を取り出すことが 不可能であった。そこで, 本実験では燃焼反応により得ら れた武料をさらにアーク溶解してインゴット状にすること を武みた。

Fig. 6 はアーク溶解した武料の光学顯微鏡組織を示す。 （a）は凝固状態のままの試料（以後, 凝固材料と呼ふ）の 組織である。アーク溶解により析出物の体積率は燃烧反応 した武料 (Fig. 5 ) と比較してほとんど変化していないが, 窒化物の形状が丸みを带びた球あるいは棒球状になってい る。(b) は凝固材料を $1423 \mathrm{~K}, 20 \mathrm{~h}$ 均一化焼鈍を行った後 の試料 (以後, 焼鈍材料と呼ふ) の組䢂を示す。このよう な烧鈍により, 窒化物の体積率はほとんど変化することは なかったが, 形状はやや球状化する傾向がみられ, サイズ もわずかに粗大化している。また, マトリックス中に微細 な点状の析出物が生じているのが観察される。

Fig. 7 はこれらの試料を薄膜にして透過電子顕微鏡によ
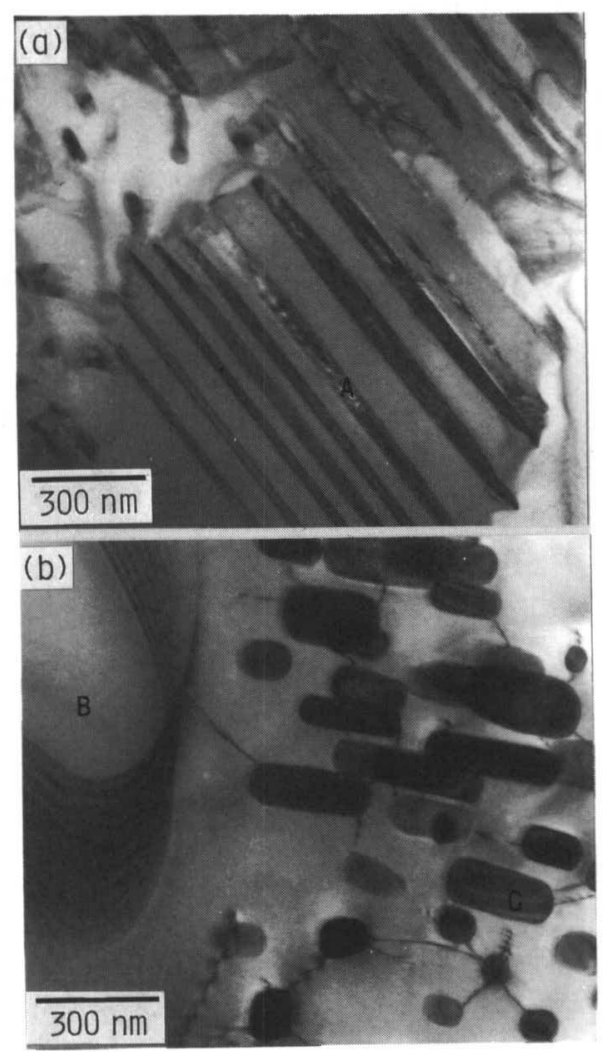

Fig. 7 TEM microstructures of a $\mathrm{Ti}_{50} \mathrm{Al}_{50}$ specimen prepared from combustion-reaction process followed by arc-melting; (a) as cast specimen, (b) annealed specimen. り観寮したものである。（a）は准固材料のマトリックスか ら得られたもので, ラメラ組織が镭察される。電子回折お よびEDS分析の結果から,このラメラ状組織 (写真 A)

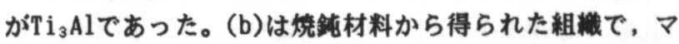
トリックス中のラメラ状組職は消失しており, 燃焼反応時 に形成された窒化物 (写真B ) とは别に，新たに $100 \mathrm{~nm}$ 程 度の直径を持つ球状あるいは棒球状の微細な析出物（写真 C ）が珰められる。電子回折およびE D S 分析の結果から この析出物も窒化物 $\mathrm{Ti}_{2} \mathrm{AlN}$ であった。これが光影写真 ( Fig. 6(b)）で恋められた点状の析出物に相当するのであ ろう。したがって, 窒素を固溶した $\mathrm{Ti}_{3} \mathrm{Al}$ 相が焼鈍遇程中 にTiAl相に変態するとき, 過剩となった窒繋が $\mathrm{Ti}_{2} \mathrm{AlN}$ とし てマトリックス中に析出したものと考えられる。

\section{III-5 圧縮試験結果}

Fig. 8 (a) に輈固材料の各温度での圧縮応力ーひずみ曲 線を示す。降伏強度は室温 873Kの間で約 $1100 \mathrm{MPa}$ と高い 值を示し，1073Kにおいて強度は低下するが約700MPa とい う高い值を維持している。この材料の延性（圧縮ひずみ） については室沮で約10\%程度であった。脆性一延性の還移 温度は TiAl単相の結果 ${ }^{6}$ 'と同棣に 973K付近と考えられ, 1073K 以上の圧縮武験の篹囲内では破断に至らなかった。 Fig. 8(b) は焼鈍材料の各温度での圧縮応力ーひずみ曲線 を示す。降伏强度は室温で䄪 $900 \mathrm{MPa}$ と凝固材料より低下し

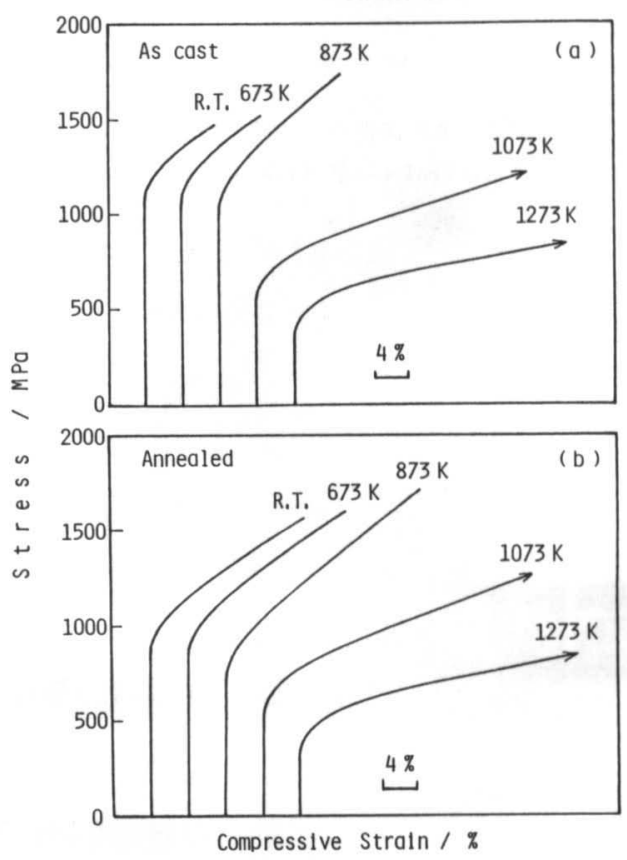

Fig. 8 Compressive stress - strain curves at various temperatures for (a) as cast specimen and (b) annealed specimen. 
たが，延性は約18\%とかなり改缮されている。

Fig.9 は，圧縮応力ーひずみ曲線から得られた0.2\%降伏 伈力を試䮩温度に対してプロットしたものである。図中に は比較のためTiAl $(\gamma)$ 単相の結果6も示した。このよう に，本実篤で得られたTiAl基裸合材料はTiAl単相に比べ室 温から高温まで $2 \sim 3$ 倍の高い強度を示している。

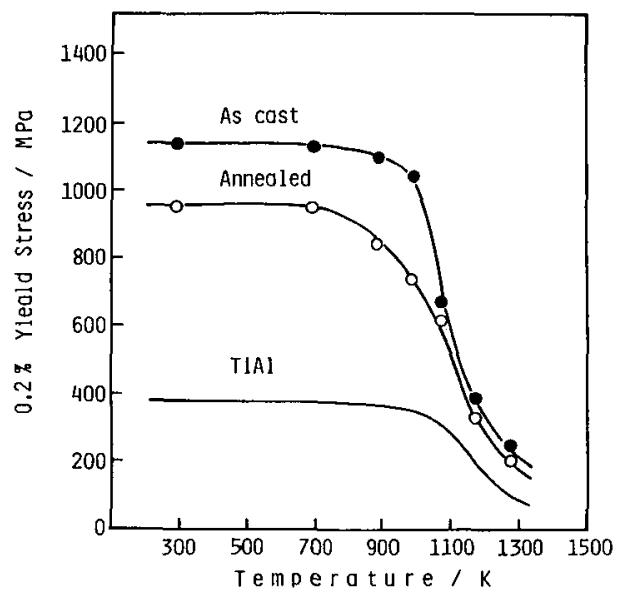

Fig. 9 Compression yield stress ( $0.2 \&$ off-set) as a function of the testing temperature for as cast specimens and annealed specimens. Included for purpose of comparison is the compression yield stress of $\mathrm{TiAl}^{6}$.

\section{IV 結 当}

$\mathrm{Ti}_{50} \mathrm{Al}_{5}$ 粗成の素粉末混合圧枌体を窒素ガス下で燃烧反

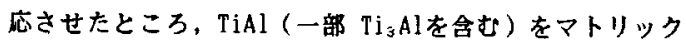

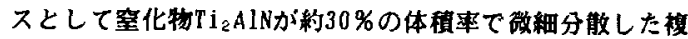
合組織材料が㧹られた。またこれらの襩合材料はアーク 溶解後も窒化物が球状化する頋向を示したか，体秘事およ び䙡合組樴状態はほぼそのまま維持されていた。得られた 複合材料は，室温～873Kで900〜 1100MPaの高い降伏强度を 示し，延性に関しても室温で䄪18\%まで圧綰変形が可能で あった。また，1173Kにおいても約400MPaの保伏蚛度を保 持していた。以上より，空素ガス下の燃焼反応プロセスを 利用した襀合組糡材料の合成は，今後有望な方法として期 待できる。

\section{文献}

1) L.Christodoulou, P.A.Parrish and C.R.Crowe : Mat. Res. Soc. Symp. Proc., Vol.120(1988),29.

2) P.Villars and L.D.Calvert : Pearson's Handbook of Crystallographic Data for Interaetallic Phases, American Sac. Met., (1985).

3) M.J. Kaufman, D.G. Konitzer, R.D. Shull and H.L. Fraser : Scripta Met., 20(1986), 103.

4) V.I. Ivchenko, M.I.Lesnaya, V.F. Nemchenko and T.Ya. Kosolapova : Inst. Mat. Sci., Academy of Sciences of the Ukrainian SSR. N.K.Krupskaya Kherson Pedagogical Insttude. Translated from Poroshkovaya Metallurgiya, No.4(160)(1976), 60 .

5) T.Lyman, ed.: Metals Handbook, Volume.8, American Society for Metals, Metals Park, ohio(1983), 264.

6) H.A.Lipsitt, D.Shechtman and R.E.Schafrik: Metall. Trans., 6A(1975), 1991. 